\title{
Correction to: Synthesis, characterization, cytotoxicity, DNA binding and computational studies of an anionic palladium(II) complex derived from 8-hydroxyquinoline and 1,1-cyclobutanedicarboxylate
}

\author{
S. Shahraki ${ }^{1}$ A. Heydari ${ }^{2}$ H. R. Mirzaei ${ }^{3} \cdot$ M. Saeidifar ${ }^{4} \cdot$ N. Ahmadi Nasab ${ }^{5} \cdot$ H. Mansouri-Torshizi ${ }^{2}$
}

Published online: 29 March 2018

(c) Iranian Chemical Society 2018

Correction to: Journal of the Iranian Chemical Society (2018) 15:697-709

https://doi.org/10.1007/s13738-017-1269-8

Unfortunately, in the original version of the article the family name of the fifth author is wrong. The correct name is displayed above.

The original article can be found online at https://doi.org/10.1007/ s13738-017-1269-8.

\section{H. R. Mirzaei}

mirzaei.hr@sbmu.ac.ir

1 Department of Chemistry, University of Zabol, Zabol, Iran

2 Department of Chemistry, University of Sistan and Baluchestan, Zahedan, Iran

3 Department of Radiation Oncology, Cancer Research Center, Shohadae Tajrish Hospital, Shahid Beheshti University of Medical Sciences, Tehran, Iran

4 Department of Nanotechnology and Advanced Materials, Materials and Energy Research Center, Karaj, Iran

5 Faculty of Pharmacy, Hormozgan University of Medical Science, Bandar Abbas, Iran 